\title{
Performance evaluation of mechanical blossom thinning in trunk type pear orchard
}

\author{
Xiaohui Lei ${ }^{1}$, Xiaolan Lyu $^{1 *}$, Meina Zhang ${ }^{1}$, Daipeng Lu $^{1}$, Shilin Wang ${ }^{1}$, Youhong Chang ${ }^{1}$, \\ Dexin Zhong ${ }^{2}$, Tianbing Shen ${ }^{3}$ \\ (1. Institute of Agricultural Facilities and Equipment, Jiangsu Academy of Agricultural Sciences/Key Laboratory of Protected Agriculture \\ Engineering in the Middle and Lower Reaches of Yangtze River, Ministry of Agriculture and Rural Affairs, Nanjing 210014, China; \\ 2. Pubei Agricultural Machinery Technology Extension Station, Qinzhou 535300, Guangxi, China; \\ 3. Tianjin Agricultural Development Service Center, Tianjin 300061, China)
}

\begin{abstract}
In order to yield a marketable product, hand fruit thinning (HFT) has become the major but costly management practice in modern pear planting. Two kinds of new blossom thinners for pear blossom thinning were developed, which are tractor-mounted three arms blossom thinner (TTBT) and hand-held electric blossom thinner (HEBT). Four treatments for 24 trunk type 'Cuiguan' pear trees (7 years) were tested. They are TTBT combined with HFT, HEBT combined with HFT, hand blossom thinning (HBT) combined with HFT, and HFT only. Pear trees were divided into 4 groups equally. Four indexes were used to evaluate the test: flower reserve rate, fruit set rate, work efficiency and cost, fruit yield, and quality. Pear canopy was divided into the inner, middle, and outer 3 layers in the top view. 20 inflorescence samples were selected for each layer. Field tests showed: there was no obvious difference in quality between mechanical blossom thinning and HBT, and the working stability of TTBT was higher than other treatments. Mechanical blossom thinning decreased the fruit set rate to a certain degree, but did not reduce the yield and quality of harvesting. TTBT could save $61.35 \%$ operation time compared with HFT, and the profitable area was $5845.76 \mathrm{~m}^{2}$. TTBT is suitable for large-scale sparse layer trunk-type pear orchards. HEBT could save $36.01 \%$ operation time compared with HFT, and the profitable area was $663.96 \mathrm{~m}^{2}$. HEBT is suitable for small and medium-sized trunk-type pear orchards. Blossom thinning can improve the average weight of high quality fruit and brix of sugar solids.
\end{abstract}

Keywords: mechanical blossom thinning, pear orchard, trunk type, performance evaluation DOI: $10.25165 /$ j.ijabe.20211404.6060

Citation: Lei X H, Lyu X L, Zhang M N, Lu D P, Wang S L, Chang Y H, et al. Performance evaluation of mechanical blossom thinning in trunk type pear orchard. Int J Agric \& Biol Eng, 2021; 14(4): 106-112.

\section{Introduction}

Pear is the third largest fruit industry in China and has been cultivated for more than 3000 years. The cultivation area, yield, and export volume of China are the first in the world now ${ }^{[1]}$. Thinning is a necessary agronomic section in pear orchard management. It can avoid biennial bearing and improve fruit quality. Although chemical thinning is fast and convenient ${ }^{[2]}$, many factors can affect it, such as variety, application time, liquid concentration, and climate ${ }^{[3-5]}$. Hand fruit thinning (HFT) is a major treatment for Chinese pear orchards nowadays. An

Received date: 2020-08-01 Accepted date: 2021-03-17

Biographies: Xiaohui Lei, Assistant Researcher, research interest: orchard management machinery and its application, Email: leixiaohui.2008@163.com; Meina Zhang, Associate Researcher, research interest: orchard pesticide application technology, Email: zmnl122@163.com; Daipeng Lu, Assistant Researcher, research interest: vegetable harvesting machinery, Email: 1dp@jaas.ac.cn; Shilin Wang, Assistant Researcher, research interest: pesticide application technology, Email: shilinag@163.com; Youhong Chang, Researcher, research interest: agricultural machinery, Email: cyh@njau.edu.cn; Dexin Zhong, Associate Researcher, research interest: agricultural machinery, Email: 386767805@qq.com; Tianbing Shen, Engineer, research interest: agricultural machinery, Email: stb0304@163.com.

*Corresponding author: Xiaolan Lyu, Researcher, research interest: orchard management machinery and its application. Institute of Agricultural Facilities and Equipment, Jiangsu Academy of Agricultural Sciences, Nanjing 210014, China. Tel: +86-25-84390493, Email: 1xlanny@126.com.
Operator needs thinning 1 to 2 times each year. HFT is labor intensive and time-consuming in pear planting. HFT is low efficiency and makes serious tree nutrient waste. It is urgent to develop high efficiency thinning machinery.

The research of mechanical thinner in China started late and the quantity was small. Wang ${ }^{[6]}$ developed a mechanical blossom thinner for dwarf dense apple and peach trees. $\mathrm{Li}$ et al. ${ }^{[7]}$ developed an electric flexible thinner for litchi trees. Hu et al. ${ }^{[8,9]}$ developed a hydraulic transmission blossom thinner based on machine vision. It can collect the blossom information according to the image collector and control the spindle rotation speed through the central controller. These machines belong to single spindle string blossom thinner. They are suitable for hedge wall type orchards and the effect on other types of trees is general. The researches of Europe and America concentrated on developing new machines early, such as electro-mechanical limb fruit thinning shaker ${ }^{[10]}$, spiked-drum blossom thinning shaker ${ }^{[11,12]}$, and single spindle string blossom thinner ${ }^{[13,14]}$. But the mature product is mainly single spindle string blossom thinner, such as the Darwin series made by Fruit $\mathrm{Tec}^{[14]}$. In the past 5 years, researches focused on new technologies, new rope materials, and new methods. Lyons et al. ${ }^{[15]}$ developed selective automated blossom thinning robotic arm for peach trees. It can remove unwanted blossoms from different branches. Wouters et al. ${ }^{[16]}$ developed pear flower buds multispectral detection system whose highest accuracy was $87 \%$. It is an attempt at intelligent blossom thinning. 
Assirelli et al. ${ }^{[17]}$ replaced the traditional rope material with flexible glass fiber in the single spindle string blossom thinner. The new thinner can save time of $48.0 \%$ and $42.4 \%$ compared with HFT in apricot and peach orchards, respectively. Pavanello et al. ${ }^{[18]}$ and Theron et al. ${ }^{[19]}$ researched the efficiency of chemicals combined with mechanical thinning for plums, getting better test results. Lordan et al. ${ }^{[20]}$ built an apple parameters prediction model on Darwin 250 single spindle string blossom thinner. It can estimate the best moving speed and spindle rotation speed by the density of inflorescence. Iwanami et al. ${ }^{[21]}$ researched a regression model for representing the relationships among crop loads, thinning time, flower bud formation, and fruit weight of apple trees. All these researches are still in the experimental stage, with no marketable product.

Mechanical blossom thinning can improve fruit yield and quality. Relative reports mostly focus on peach and apple, rarely on pear. The import price of Darwin series blossom thinner is expensive, and it is unsuitable for the trunk type orchard. To relieve the heavy labor pressure in HFT and improve the efficiency of orchard management, two kinds of new mechanical devices for Chinese pear blossom thinning were developed, which are tractor-mounted three arms blossom thinner (TTBT) and hand-held electric blossom thinner (HEBT). TTBT is designed for large-scale sparse layer trunk type pear orchards and HEBT is designed for small and medium-sized trunk type pear orchards. In this study, Cuiguan pear was taken as the research object to evaluate the effect of mechanical blossom thinning in trunk-type pear orchard. The research is expected to improve the working quality of mechanical blossom thinner and provides a reference to the mechanization management of the pear orchard.

\section{Materials and methods}

\subsection{Thinning machines}

\subsubsection{Hand-held electric blossom thinner}

HEBT is compact, easy to carry, and suitable for different canopy types. The structure of HEBT is shown in Figure 1. When working in the field, the operator ties the power bag on the waist and holds the governor in hand for thinning. The operator can adjust the spindle rotation speed according to the stalk hardness and blossom density. HEBT installation extension rod can thin the canopy in long distance, and HEBT without extension rod can thin the canopy in short distance. The main structure and performance parameters of HEBT are listed in Table 1.

2.1.2 Tractor-mounted three arms blossom thinner

The structure of TTBT is shown in Figure 2, the main structure and performance parameters of TTBT are listed in Table 2. The tractor PTO drives the hydraulic pump through the transmission shaft. The hydraulic pump provides power to the hydraulic cylinder, and the liquid distribution valve controls the extension movement of the hydraulic cylinder. The hydraulic cylinder makes the movable beam move horizontally relative to the frame. Three governors are placed in the electric cabinet, to control the spindle rotation speed of the upper, middle, and lower thinner arms. Two vertical rods are connected with each other through the flange, which can be separated and combined according to the height of the tree. Three thinner arms are installed flexibly in different positions of the vertical rod. Relative to the vertical rod, the arm bracket can rotate $360^{\circ}$ at arrow I direction. Relative to the arm bracket, the arm extension rod can rotate $360^{\circ}$ at arrow II direction and move in the range of 0 to $0.5 \mathrm{~m}$ at arrow III direction.
Relative to the arm bracket, the spindle power assembly can rotate $270^{\circ}$ at arrow IV direction.

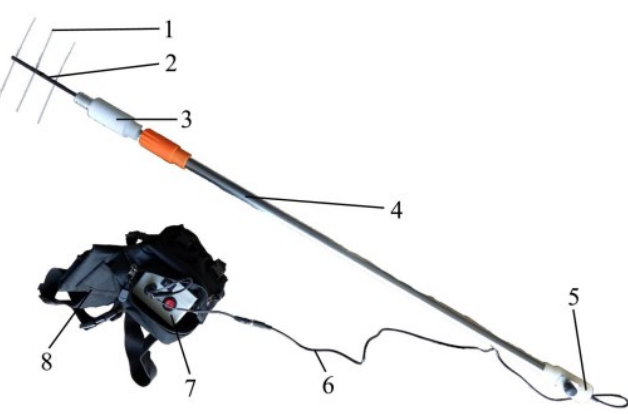

a. With extension rod

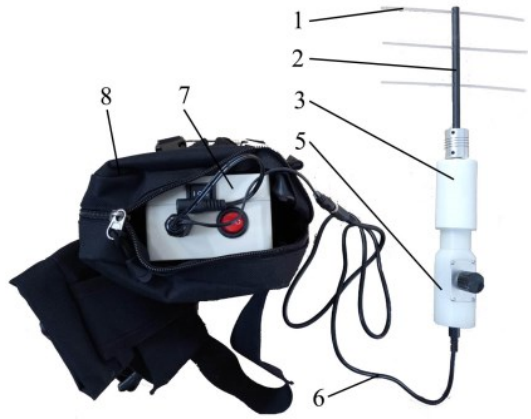

b. Without extension rod

1. Rope 2. Spindle 3. DC motor 4. Extension rod 5. Governor 6. Wire 7. Storage battery 8 . Power bag

Figure 1 Structure of HEBT

Table 1 Main structure and performance parameters of HEBT

\begin{tabular}{lc}
\multicolumn{1}{c}{ Parameter } & Value \\
\hline Rope rotation radius $/ \mathrm{cm}$ & 8 \\
Rope line diameter $/ \mathrm{mm}$ & 2.4 \\
Rope axial distance $/ \mathrm{cm}$ & 4 \\
Spindle rotation speed range $/ \mathrm{r} \cdot \mathrm{min}^{-1}$ & $0-900$ \\
Extension rod length $\mathrm{range} / \mathrm{m}$ & $0.95-1.60$ \\
Battery output voltage $/ \mathrm{V}$ & 12 \\
Battery capacity/Ah & 10.4 \\
\hline
\end{tabular}

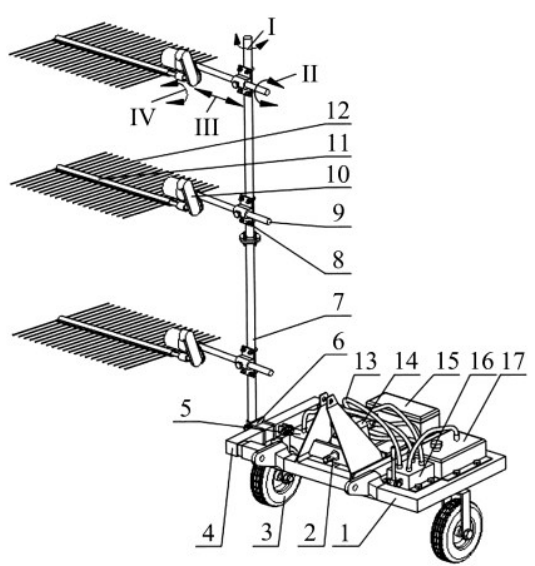

1. Frame 2. Transmission shaft 3. Limit wheel 4. Movable beam 5. Hydraulic cylinder 6. Vertical rod bracket 7. Vertical rod 8. Arm bracket 9. Arm extension rod 10. Spindle power assembly 11. Spindle 12. Rope 13. Hydraulic pipeline 14. Hydraulic pump 15. Electric cabinet 16. Liquid distribution valve 17. Hydraulic oil tank

Note: I is the rotation direction of arm bracket; II is the rotation direction of arm extension rod; III is the movement direction of arm extension rod; IV is the rotation direction of spindle power assembly.

Figure 2 Structure of TTBT 
Table 2 Main structure and performance parameters of TTBT

\begin{tabular}{lc}
\multicolumn{1}{c}{ Parameter } & Value \\
\hline Tractor minimum power $/ \mathrm{kW}$ & 18.8 \\
Weight $/ \mathrm{kg}$ & 200 \\
Size $($ length $\times$ width $\times$ height $) / \mathrm{m} \times \mathrm{m} \times \mathrm{m}$ & $0.9 \times 1.2 \times 2.7$ \\
Arm number & 3 \\
Arm extension range $/ \mathrm{m}$ & $0-0.5$ \\
Spindle length $/ \mathrm{m}$ & 1.1 \\
Spindle rotation speed range $/ \mathrm{r} \cdot \mathrm{min}^{-1}$ & $0-300$ \\
Rope rotation radius $/ \mathrm{m}$ & 0.5 \\
Rope line diameter $/ \mathrm{mm}$ & 3 \\
Rope axial distance $/ \mathrm{cm}$ & 4 \\
\hline
\end{tabular}

\subsection{Field tests}

\subsubsection{Conditions}

Tests of four blossom thinning treatments were conducted in Ye Jia pear orchard, Tai Xing, Jiang Su province. The trees were 7 years old $(7 \mathrm{a})$, and were planted $5 \mathrm{~m}$ between rows and $3 \mathrm{~m}$ within rows. The trees were $3 \mathrm{~m}$ tall on average. The average trunk height was $0.6 \mathrm{~m}$ and the average trunk diameter was $8 \mathrm{~cm}$. The flower buds were thinned from March 22 to 24, 2020, $7 \mathrm{~d}$ before full bloom (flower bud was easy to thin). The fruits were thinned from April 20 to 28, 2020 and harvested from July 25 to 31, 2020. The test tractor was a LOVOL M604L-E (Lovol Heavy Industry Co., Ltd., Weifang, Shandong, China). Because the branches and leaves blocked the sight of the driver easily during the tractor movement, low speed gear was used as working power (tractor moving speed was $0.31 \mathrm{~m} / \mathrm{s}$ ) during the test. Referring to the thinner rope impact forces model and test previously ${ }^{[22]}$, the spindle rotation speed of TTBT and HEBT were set to $250 \mathrm{r} / \mathrm{min}$ and $500 \mathrm{r} / \mathrm{min}$, respectively.

The minor branches of trunk type pear tree were long, and the main branch angles with the ground were large, which was not conducive to the work of the thinner arms extending into the tree canopy. The situation that about $13 \%$ of flowers on one pear tree growing into fruits is perfect, and appropriate sparse layer pruning will not affect the quality and fruit yield. To adapt the pear tree for TTBT, the canopy was adjusted from trunk type to sparse layer trunk type. 6 trunk-type pear trees in the field were selected and adjusted in the winter of 2017. After a growth and adaptation period of 2 years in 2018 and 2019, they were applied to the test in 2020. The shape of the canopy before and after adjustment is shown in Figure 3.

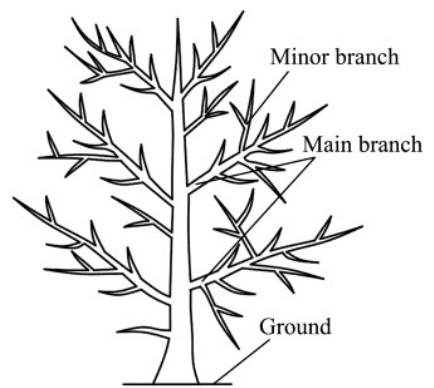

a. Trunk type tree

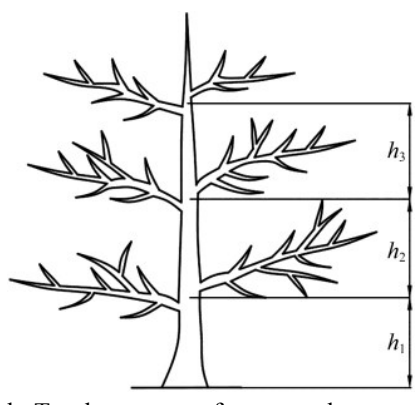

b. Trunk type tree after sparse layer
Note: Selection criteria of trees to adjust is that canopy keeps 3 layers main branches, and the length range of $h_{1}, h_{2}, h_{3}$ is $0.6 \mathrm{~m}$ to $0.8 \mathrm{~m}$. The method to adjust tree canopy is pruning the overlong minor branches, and decreasing the angle between the main branch and the ground horizontal plane by traction.

Figure 3 Shape of canopy before and after adjustment

\subsubsection{Treatments}

Four kinds of treatments were conducted to evaluate the efficiency of blossom thinning, which were TTBT combined with HFT, HEBT combined with HFT, hand blossom thinning (HBT) combined with HFT, and HFT only. Test indexes were flower reserve rate ${ }^{[23]}$, fruit set rate, work efficiency and cost, fruit yield and quality ${ }^{[24,25]}$. Six trunk-type trees with sparse layers were used for TTBT, and another eighteen trunk-type trees were selected as the test objects of HEBT, HBT, and HFT. The 18 trees were divided equally into 3 groups. HFT only was set as the control group and 3 other groups were set as the test groups.

The movement path of TTBT is shown in Figure 4. The tractor moved along the ' $\mathrm{S}$ ' shaped route to complete the pear tree blossom thinning. The trunk central point deviated from the tree central line at a certain distance. To ensure the arm does not collide with the main trunk of the pear tree, the right-most arm should keep some distance from the tree central line. This makes it impossible for the thinner to work in the area near the trunk central point, especially the area between trees within rows. Operators of the other 2 blossom thinning treatments can flexibly work on various areas of the canopy, and no such problem exists. Therefore, the sample point arrangement method is as follows: the tree canopy shown in Figure 5 was divided equally into inner, middle, and outer 3 layers and each layer was divided equally into 4 sections (12 sections totally). 5 inflorescence samples of each section were selected equally in the direction of tree height.

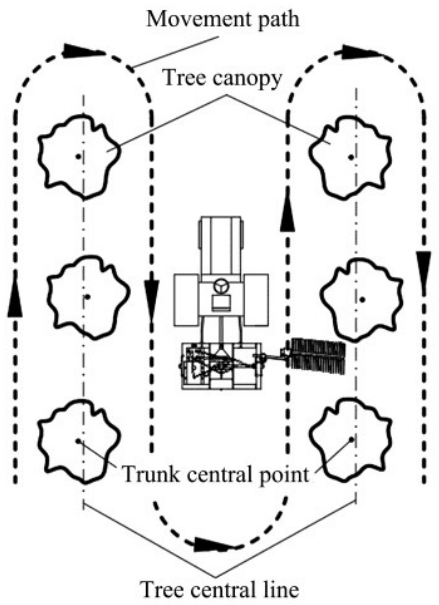

Figure 4 Movement path of TTBT

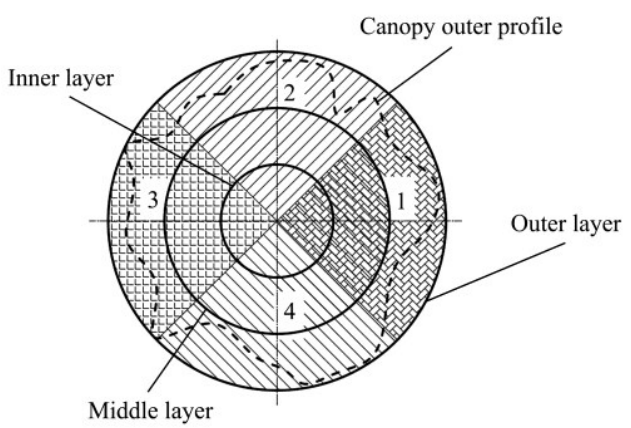

Figure 5 Canopy division

Blossom thinning tests were carried out from March 22 to 24, 2020. The flower bud number of the inflorescence samples before and after thinning, and the thinning time of each tree were recorded Fruit thinning tests were carried out from April 22 to 25, 2020. The green fruit number of the inflorescence samples before and after thinning, and the thinning time of each tree was recorded. Harvesting tests were carried out from July 28 to $30,2020$. Referring to national standard NY/T440 $0^{[26]}$ and GB/T10650 $0^{[27]}$, the fruits of each test pear tree were graded for high-quality fruits and 
ordinary fruits. The high-quality fruit is defined as that the shape is correct, the peel is dark green, the fruit stem is intact, the fruit surface is free from stab, scratch, crush, grind, worm, and the mass of the single fruit is not less than $350 \mathrm{~g}$. In each treatment, 3 fruits were selected from the high-quality fruits and the ordinary fruits respectively, and the brix of sugar solid of each fruit was measured. Then, the average value of these 6 fruits was calculated to obtain the brix of sugar solid for each treatment. The work field of mechanical blossom thinner and flower buds after thinning are shown in Figure 6. In the test, except for tractor driving, 2 skilled workers were selected for the operations and one person was responsible for one tree.

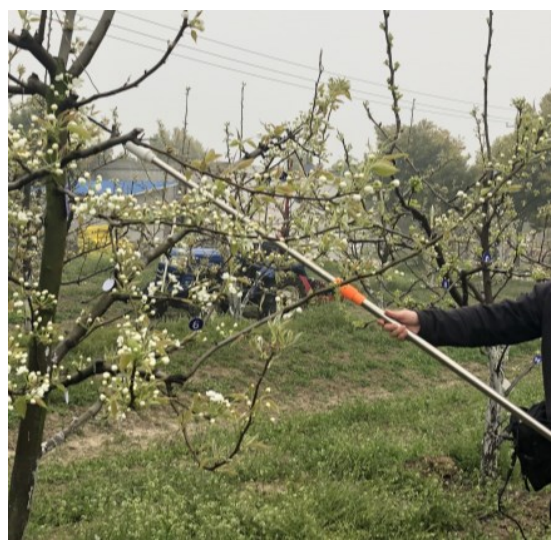

a. Work field of HEBT

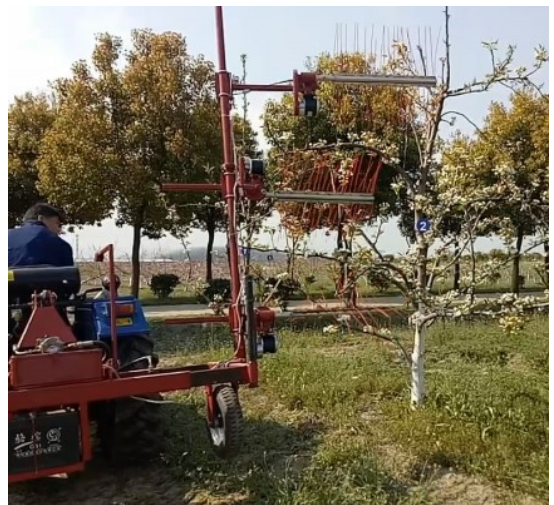

b. Work field of TTBT

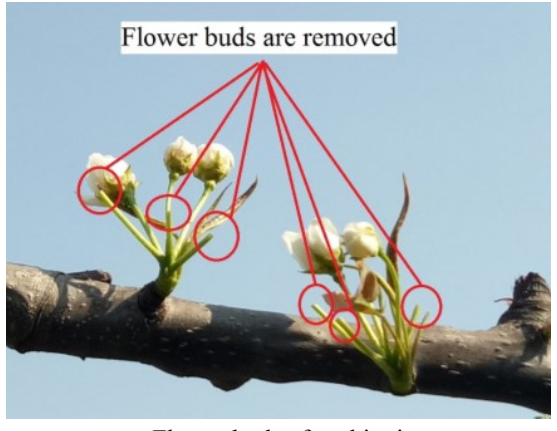

c. Flower buds after thinning

Figure 6 Work field of mechanical blossom thinner and flower buds after thinning

Asteggiano et al. ${ }^{[28]}$ performed mechanical blossom thinning on peach tree (single bud) and the average flower reserve rate was $60 \%$. McClure et al. ${ }^{[29]}$ performed mechanical blossom thinning on apple tree (mixed buds) and the average flower reserve rate was $54.5 \%$. Huang et al. ${ }^{[30]}$ suggested that pear trees (mixed buds) should reserve 1 to 3 flowers for each inflorescence. Each inflorescence of 'Cuiguan' pear has an average of 6 flowers, and flower reserve rate ranges from $20 \%$ to $50 \%$. Considering the objective factors of fruit growth such as weather regurgitation, blossom thinning damage, flower pollination, pecking of insects and birds, natural fruit fall, and proportion confirmation, the flower bud reserve rate of 4 treatments was set at $50 \%$, and flower bud reserve rate was defined as the number of sample flower bud after blossom thinning divided by the number of sample flower bud before blossom thinning.

\section{Results and discussion}

\subsection{Flower bud reserve rate}

The flower bud reserve rate of the inflorescence sample was tested to evaluate the quality of the 3 blossom thinning treatments. To reflect the individual stability of the thinning on a pear tree, the coefficient variation of the flower bud reserve rate in different layers was calculated. The calculation formulas of flower bud reserve rate, standard deviation, and coefficient variation are shown in Equations (1)-(3). The results are listed in Table 3.

$$
c=\frac{\sum_{i=1}^{6} c_{i}}{6}
$$

where, $c_{i}$ is the flower bud reserve rate of tree $i, \% ; c$ is flower bud reserve rate, $\%$

$$
S_{c}=\sqrt{\frac{\sum_{i=1}^{6}\left(c_{i}-c\right)^{2}}{6}}
$$

where, $s_{c}$ is the standard deviation of the flower bud reserve rate, $\%$.

$$
\mathrm{CV}=\frac{s_{c}}{c} \times 100 \%
$$

where, $\mathrm{CV}$ is the coefficient variation of the flower bud reserve rate, $\%$.

\begin{tabular}{|c|c|c|c|c|c|}
\hline Position & Index & HFT & HBT & HEBT & TTBT \\
\hline \multirow{2}{*}{ Inner layer } & $c / \%$ & 100 & 54.18 & 54.98 & 56.47 \\
\hline & $\mathrm{CV} / \%$ & -- & 4.47 & 9.04 & 2.41 \\
\hline \multirow{2}{*}{ Middle layer } & $c / \%$ & 100 & 51.40 & 53.26 & 57.00 \\
\hline & $\mathrm{CV} / \%$ & -- & 3.91 & 6.87 & 1.70 \\
\hline \multirow{2}{*}{ Outer layer } & $c / \%$ & 100 & 48.75 & 51.61 & 56.22 \\
\hline & $\mathrm{CV} / \%$ & -- & 2.75 & 3.85 & 2.17 \\
\hline \multicolumn{2}{|c|}{ Average $c / \%$} & 100 & 51.44 & 53.28 & 56.56 \\
\hline \multicolumn{2}{|c|}{ Average $\mathrm{CV} / \%$} & -- & 3.71 & 6.59 & 2.09 \\
\hline
\end{tabular}

Table 3 Flower bud reserve rate $c$ and coefficient variation CV

Note: HFT represents hand fruit thinning; HBT represents HBT+HFT; HEBT represents HEBT+HFT; TTBT represents TTBT+HFT, the same as below.

The flower bud reserve rate of three test groups is HBT $51.44 \%$, HEBT $53.28 \%$, and TTBT $56.56 \%$, and all can meet the need for blossom thinning. The order of coefficient variation of flower bud reserve rate ranking from small to large is TTBT, HBT, and HEBT. The coefficient variation of flower bud reserve rate of TTBT is $1.62 \%$ and $4.50 \%$ lower than that of HBT and HEBT, respectively. This is related to the mechanized operation of TTBT: tractor of TTBT followed a fixed route and was more stable than HBT and HEBT which repeatedly moved around the tree canopy. The coefficient variation of flower bud reserve rate of HEBT is the largest in test groups, showing that it is more difficult to ensure the uniformity of blossom thinning than HBT and TTBT. The fatigue caused by long time operation will have a great impact on the accuracy, and the effect of fatigue of HEBT is larger than that of HBT. HEBT was carried out by the operator's hand, and the 
contact range between the rope and the flower bud was controlled by the operator subjectively. The flower bud reserve rate and its coefficient variation of HBT and HEBT showed a decreasing trend from the inner layer to the outer layer, which was related to the difficulty of thinning. The farther away from the trunk center point, the less the operator is blocked by the branches, the more convenient the blossom thinning is, and the higher the blossom thinning stability is. The flower bud reserve rate of the TTBT is the highest in the test groups because it could not completely thin zones 2 and 4 in Figure 5. The detailed flower bud reserve rates of TTFT at 4 zones are listed in Table 4 . The average flower bud reserve rate of zones 1 and 3 is $50.72 \%$, while the average flower bud reserve rate of zones 2 and 4 is $62.40 \%$.

Table 4 Flower bud reserve rate $c$ of tractor-mounted three arms blossom thinner

\begin{tabular}{lcc}
\hline \multicolumn{1}{c}{ Position } & $c$ of zones 1 and $3 / \%$ & $c$ of zones 2 and $4 / \%$ \\
\hline Inner layer & 50.48 & 62.46 \\
Middle layer & 51.15 & 62.85 \\
Outer layer & 50.54 & 61.90 \\
Average & 50.72 & 62.40 \\
\hline
\end{tabular}

\subsection{Fruit set rate}

The purpose of HFT is to improve fruit yield and quality, and the purpose of blossom thinning is to relieve the heavy labor pressure of HFT and improve working efficiency. Some flower buds hit by the ropes will slowly wither during the growth. Relative fruit set rate is a better index to evaluate the blossom thinning quality and it can remove the interference of flower bud reserve rate. The relative fruit set rate was defined as the number of sample green fruit before fruit thinning divided by the number of sample flower bud after blossom thinning. The calculation method of relative fruit set rate and its coefficient variation is the same as that of flower bud reserve rate. The results are listed in Table 5 .

Table 5 Relative fruit set rate $s$ and coefficient variation $\mathrm{CV}$

\begin{tabular}{cccccc}
\hline Position & Index & HFT & HBT & HEBT & TTBT \\
\hline \multirow{2}{*}{ Inner layer } & $s / \%$ & 80.98 & 85.59 & 77.32 & 70.16 \\
& $\mathrm{CV} / \%$ & 2.60 & 2.18 & 7.78 & 3.32 \\
\hline \multirow{2}{*}{ Middle layer } & $s / \%$ & 80.24 & 85.11 & 75.16 & 69.02 \\
& $\mathrm{CV} / \%$ & 2.94 & 2.13 & 6.07 & 2.09 \\
\hline \multirow{2}{*}{ Outer layer } & $s / \%$ & 80.14 & 84.73 & 74.07 & 68.77 \\
& $\mathrm{CV} / \%$ & 2.42 & 1.66 & 4.96 & 2.33 \\
\hline \multicolumn{2}{c}{ Average $s / \%$} & 80.45 & 85.14 & 75.52 & 69.32 \\
\multicolumn{2}{c}{ Average $\mathrm{CV} / \%$} & 2.65 & 1.99 & 6.27 & 2.58 \\
\hline
\end{tabular}

The order of the relative fruit set rate of each group ranking from small to large is TTBT, HEBT, HFT, and HBT. The relative fruit set rate of HFT is $4.93 \%$ and $11.13 \%$ higher than that of HEBT and TTBT, respectively. It shows the mechanical blossom thinning has some influence on the fruit set of trees, and the effect of TTBT is higher than that of HEBT. The relative fruit set rate and its coefficient variation of HBT and HEBT showed a decreasing trend from the inner layer to the outer layer, and the trend was positively related with flower bud reserve rate and its coefficient variation in Table 3. The relative fruit set rate of HBT is $4.69 \%$ higher than that of HFT, showing that HBT could reduce the natural fruit drop of pear trees to a certain degree. The flower bud reserve rate of TTBT in Table 3 is higher than that of HBT and HEBT, but the relative fruit set rate of TTBT in Table 5 is lower than that of HBT and HEBT. Part of the reason is that TTBT cannot completely work on the zones 2 and 4 in Figure 5, resulting in a higher flower bud reserve rate in Table 3. Another reason is that the relative fruit set rate of TTBT is relatively lower. The relative fruit set rate of TTBT at zones 1, 3 and 2, 4 are listed in Table 6, which is $14.77 \%$ and $7.50 \%$ lower than HFT in Table 5, respectively.

Table 6 Relative fruit set rate $s$ of tractor-mounted three arms blossom thinner

\begin{tabular}{lcc}
\hline \multicolumn{1}{c}{ Position } & $s$ of zones 1 and $3 / \%$ & $s$ of zones 2 and $4 / \%$ \\
\hline Inner layer & 66.54 & 73.78 \\
Middle layer & 64.58 & 73.46 \\
Outer layer & 65.93 & 71.60 \\
Average & 65.68 & 72.95 \\
\hline
\end{tabular}

\subsection{Working efficiency and cost}

The higher the work efficiency, the lower the management cost Even if each tree has the same age and shape, the number of flowers and fruits is different, and the working efficiency is different. To reduce the test error, the thinning time of each tree was recorded and the average value was calculated. The results are listed in Table 7.

Table 7 Average thinning time of one tree

\begin{tabular}{lcccc}
\hline \multicolumn{1}{c}{ Name } & HFT & HBT & HEBT & TTBT \\
\hline Blossom thinning time/min & -- & 23.03 & 11.65 & 0.32 \\
Fruit thinning time/min & 60.23 & 32.31 & 26.89 & 22.96 \\
Total time/min & 60.23 & 55.34 & 38.54 & 23.28 \\
\hline
\end{tabular}

The total thinning time of the test groups is shorter than the control group. It ranked from long to short in the order of HBT, HEBT, and TTBT. The total time-saving proportion of HBT, HEBT and TTBT to the control group is $8.12 \%, 36.01 \%$, and $61.35 \%$, respectively. The proportion of blossom thinning time to fruit thinning time is HBT $71.28 \%$, HEBT $43.32 \%$, and TTBT $1.39 \%$. Working efficiency of 4 groups ranked from high to low in the order of TTBT, HEBT, HBT, and HFT. The profitable area of the machine is the minimum planting area required by machines to replace labor in management cost. When the planting area of crops is larger than the profitable area, the machine can bring profits. The price of TTBT and HEBT is 15000 yuan and 1000 yuan respectively, with 5 years of depreciable life. Labor cost is 100 yuan in an eight-hour day. The planting space of one tree is $15 \mathrm{~m}^{2}$. According to Equations (4)-(6), the profitable area of TTBT and HEBT is $5845.76 \mathrm{~m}^{2}$ and $663.96 \mathrm{~m}^{2}$, respectively.

$$
q=\frac{p}{n}
$$

where, $q$ is the annual depreciation of one thinner, yuan; $p$ is the price of one thinner, yuan; $n$ is the depreciable life, year.

$$
d=\frac{d_{0} t}{t_{0} A_{0}} \times \eta
$$

where, $d$ is the saving cost of one thinner by replacing labor, yuan $/ \mathrm{m}^{2} ; d_{0}$ is the labor cost in an eight-hour day, yuan; $t$ is the average fruit thinning time of one tree in the control group, $\mathrm{h} ; t_{0}$ is the working hours of one day, $\mathrm{h} ; A_{0}$ is the ground space of one tree, $\mathrm{m}^{2} ; \eta$ is the time-saving proportion of test group to control group.

$$
A=\frac{q}{d}
$$

where, $A$ is the profitable area of one thinner, $\mathrm{m}^{2}$.

\subsection{Fruit yield and quality}

Fruit yield and quality are important indexes to evaluate the quality of orchard production, which is directly related to the 
income of the manager. Fruit reserve rate, total yield per tree, high-quality fruit yield per tree, the average mass of high-quality fruit and brix of sugar solids were discussed. The fruit reserve rate was defined as the number of sample ripe fruit divided by the number of sample flower bud before blossom thinning. The results are shown in listed 8 .

Table 8 Fruit yield and quality

\begin{tabular}{lcccc}
\hline \multicolumn{1}{c}{ Index } & HFT & HBT & HEBT & TTBT \\
\hline Fruit reserve rate/\% & 13.24 & 12.99 & 12.89 & 12.78 \\
Total yield per tree/kg & 44.58 & 42.83 & 42.17 & 42.08 \\
High quality fruit yield per tree/kg & 23.41 & 21.59 & 21.22 & 20.47 \\
Average mass of high quality fruit/g & 360.15 & 378.77 & 385.82 & 393.65 \\
Brix of sugar solids/\% & 12.80 & 13.10 & 13.10 & 13.20 \\
\hline
\end{tabular}

Note: The high quality fruit is defined as that the shape is correct, the peel is dark green, the fruit stem is intact, the fruit surface is free from stab, scratch, crush, grind, worm, and the mass of the single fruit is not less than $350 \mathrm{~g}$.

The average fruit reserve rate of 4 treatments is $12.98 \%$, which meets the planting requirement of $13 \%{ }^{[31]}$. The fruit reserve rate is positively related to the total yield and the high-quality fruit yield, and negatively related to the average mass of high-quality fruit and brix of sugar solids. There is no obvious difference among the test groups. After averaging, the fruit reserve rate is $12.89 \%$, the total yield per tree is $42.36 \mathrm{~kg}$, the high-quality fruit yield per tree is $21.09 \mathrm{~kg}$, the average mass of high-quality fruit is $386.08 \mathrm{~g}$, and the brix of sugar solids is $13.13 \%$. Compared with the control group, the fruit reserve rate decreased by $2.64 \%$, the total yield per tree decreased by $4.98 \%$, the high-quality fruit yield per tree decreased by $9.91 \%$, the high-quality fruit yield per tree increased by $7.2 \%$, and the brix of sugar solids increased by $2.58 \%$. The fruit reserve rate, the total yield per tree, and the high-quality fruit yield per tree of the control group are higher than those of the test groups. This is because the leaves of the tree that formed in the period of fruit thinning and the thick leaves block the operator's sight. The number of green fruit for thinning in the test group is only about $50 \%$, which is less affected than that in the control group. The average mass of high-quality fruit and the brix of sugar solids in the control group are lower than those in the test group, which is related to the nutrient waste of fruit trees. The control group only had fruit thinning and almost $80 \%$ of flower bud developed into green fruit. About $50 \%$ of flower buds were thinned in test groups and the number of flower buds that developed into green fruit was less than that in the control group.

\section{Conclusions}

1) The study introduced two kinds of mechanical pear blossom thinner that developed in the early stage. HEBT can be assembled flexibly according to working conditions, the spindle rotation speed is adjustable from 0 to $900 \mathrm{r} / \mathrm{min}$, the length of the extension rod is adjustable from $0.95 \mathrm{~m}$ to $1.60 \mathrm{~m}$, the battery capacity is $10.4 \mathrm{Ah}$, and it can work continuously for more than $8 \mathrm{~h}$. TTBT is suspended and driven by tractor. The position of the thinner arm can be adjusted from multiple angles. The spindle length is $1.1 \mathrm{~m}$ and the rotation speed is adjustable from 0 to $300 \mathrm{r} / \mathrm{min}$.

2) 4 thinning treatments (TTBT combined with HFT, HEBT combined with HFT, HBT combined with HFT, and HFT only) were tested on trunk type "Cuiguan" pear. 4 indexes (flower reserve rate, fruit set rate, work efficiency and cost, fruit yield and quality) were used to evaluate the test. There is no obvious difference in quality between mechanical and artificial blossom thinning, and the operational stability of TTBT is higher than that of other treatments. Mechanical blossom thinning decreases the fruit set rate to a certain degree, but does not reduce the yield and quality of harvesting. TTBT can save $61.35 \%$ operation time compared with HFT, and the profitable area is $5845.76 \mathrm{~m}^{2}$, which is suitable for large-scale sparse layer trunk type pear orchard. HEBT can save $36.01 \%$ operation time compared with HFT, and the profitable area is $663.96 \mathrm{~m}^{2}$, which is suitable for small and medium-sized trunk type pear orchards. Blossom thinning can improve the average weight of high-quality fruit and brix of sugar solids.

\section{Acknowledgements}

This work was supported by Jiangsu Agricultural Science and Technology Innovation Fund (Grant No. CX(20)3058), Jiangsu Modern Agricultural Machinery Equipment and Technology Demonstration Extension Fund (Grant No. NJ2019-24), National Key Research and Development Program of China (Grant No. 2018YFD0201400), China Agriculture Research System of MOF and MARA (Grant No. CARS-28), and National Natural Science Foundation of China (Grant No. 61803187).

\section{[References]}

[1] Wang W, Wang G, Tian L, Li X, Lyu X, Zhang Y, et al. Fruit scientific research in New China in the past 70 years: Pear. Journal of Fruit Science, 2017; 36(10): 1273-1282. (in Chinese)

[2] Yang G, Zhang J, Tian J, Yao Y. Study on thinning effects of three thinning agents to pear flowers and fruits. Journal of Beijing University of Agriculture, 2017; 32(1): 18-23. (in Chinese)

[3] Robinson T L, Lakso A N. Predicting chemical thinner response with a carbohydrate model. Acta Horticulturae, 2011; 903: 743-750.

[4] Miller S S, Tworkoski T. Blossom thinning in apple and peach with an essential oil. HortScience, 2010; 45: 1218-1225.

[5] Hampson C, Bedford K. Efficacy of blossom thinning treatments to reduce fruit set and increase fruit size of ambrosia and aurora golden gala apples. Canadian Journal of Plant Science, 2011; 91: 983-990.

[6] Wang Q. Design and research of mechanical blossom thinning device for the dwarf dense fruit trees. Master dissertation. Baoding: Hebei Agricultural University, 2018; 71 p. (in Chinese)

[7] Li J, Xu Y, Xu J T, Yang Z, Lu H Z. Design and experiment of control system for suspended electric flexible thinner. Transactions of the CSAE, 2016; 32(18): 61-66. (in Chinese)

[8] Hu C, Sun C, Ji J. Performance experimental and analysis on mechanical thinning flower actuator. Journal of Chinese Agricultural Mechanization, 2015; 36(5): 24-28. (in Chinese)

[9] Sun C, Hu C, Hou Q, Pan Z. Simulation of mechanical thinning flower actuator based on ADAMS. Journal of Agricultural Mechanization Research, 2015; 37(12): 70-73. (in Chinese)

[10] Rosa U A, Cheetancheri K G, Gliever C J, Lee S H, Thompson J, Slaughter D C. An electro-mechanical limb shaker for fruit thinning. Computer and Electronics in Agriculture, 2008; 61: 213-221.

[11] Schupp J R, Baugher T A, Miller S S, Harsh R M, Lesser K M Mechanical thinning of peach and apple trees reduces labor input and increases fruit size. Horttechnology, 2008; 18(4): 660-670.

[12] Miller S S, Schupp J R, Baugher T A, Wolford S D. Performance of mechanical thinners for bloom or green fruit thinning in peaches. HortScience, 2011; 46(1): 43-51.

[13] Baugher T A, Ellis K, Remcheck J, Lesser K, Schupp J, Winzeler E, et al Mechanical string thinner reduces crop load at variable stages of bloom development of peach and nectarine trees. HortScience, 2010; 45(9): 1327-1331.

[14] Baugher T A, Schupp J, Ellis K, Remcheck J, Winzeler E, Duncan R, et al. String blossom thinner designed for variable tree forms increases crop load management efficiency in trials in four United States peach-growing regions. HortScience, 2010; 20(2): 409-414.

[15] Lyons D J, Heinemann P H, Schupp J R, Baugher T A, Liu J. Development of a selective automated blossom thinning system for peaches. Transactions of the ASABE, 2015; 58(6): 1447-1457.

[16] Wouters N, Ketelaere B D, Deckers T, Baerdemaeker J D, Saeys W. 
Multispectral detection of floral buds for automated thinning of pear. Computers and Electronics in Agriculture, 2015; 113: 93-103.

[17] Assirelli A, Giovannini D, Cacchi M, Sirri S, Baruzzi G, Caracciolo G. Evaluation of a new machine for flower and fruit thinning in stone fruits. Sustainability, 2018; 10: 4088. doi: 10.3390/su10114088

[18] Pavanello A P, Zoth M, Ayub R A. Manage of crop load to improve fruit quality in plums. Revista Brasileira De Fruticultura, 2018; 40(4): 721. doi: 10.1590/0100-29452018721

[19] Theron K I, Steenkamp H, Steyn W J. Efficacy of ACC (1-aminocyclopropane-1-carboxylic acid) as a chemical thinner alone or combined with mechanical thinning for Japanese plums (Prunus salacina). HortScience, 2017; 52(1): 110-115.

[20] Lordan J, Alins G, Àvila G, Torres E, Carbó J, Bonany J, et al. Screening of eco-friendly thinning agents and adjusting mechanical thinning on 'Gala', 'Golden Delicious' and 'Fuji' apple trees. Scientia Horticulturae, 2018; 239: 141-155.

[21] Iwanami H, Moriya-Tanaka Y, Honda C, Hanada T, Wada M. A model for representing the relationships among crop load, timing of thinning, flower bud formation, and fruit weight in apples. Scientia Horticulturae, 2018; 242: 181-187.

[22] Lei X, Lv X, Zhang M, Li X, Chang Y, Herbst A. Development and test of three arms tractor-mounted flower thinner. Transactions of the CSAE, 2019; 35(24): 31-38. (in Chinese)

[23] Sauerteig K A, Cline J A. Mechanical blossom thinning of 'Allstar' peaches influences yield and quality. Scientia Horticulturae, 2013; 160:
243-250.

[24] Han W, Han N, He X, Zhao X. Berry thinning to reduce bunch compactness improves fruit quality of Cabernet Sauvignon (Vitis vinifera L.). Scientia Horticulturae, 2019; 246: 589-596.

[25] Barreto C F, Antunes L E C, Ferreira L V, Navroski R, Benati J A, Pereira J F M. Mechanical flower thinning in peach trees. Revista Brasileira De Fruticultura, 2019; 41(6): 465. doi: 10.1590/0100-29452019465

[26] Ministry of Agriculture and Rural Affairs of the People's Republic of China Standards for appearance grades of pears, 2001; NY/T 440: 2001. (in Chinese)

[27] Inspection and Quarantine of the People's Republic of China (AQSIQ). Fresh pears, 2008; GB/T 10650: 2008. (in Chinese)

[28] Asteggiano L, Giordani L, Bevilacqua A, Vittone G, Pellegrino S, Costa G Bloom mechanical thinning improves fruit quality and reduces production costs in peach. Acta Horticulturae, 2015; 1084: 389-394.

[29] McClure K A, Cline J A. Mechanical blossom thinning of apples and influence on yield, fruit quality and spur leaf area. Canadian Journal of Plant Science, 2015; 95: 887-896.

[30] Huang Z, Liu Z, Shu Q, Jiang G. Research of flower and fruit thinning on 'Cuiguan' pear. Shanghai Agricultural Science and Technology, 2011; 1: 60. (in Chinese)

[31] Huang Z, Bao J, Chen Y, Chen X, Zhang C, Zhang C, et al. Cause analysis and preventive measures of the low fruiting rate of 'Cuiguan' pear in Fujian Province. South China Fruits, 2011; 40(6): 53-55. (in Chinese) 